\begin{tabular}{c} 
Volume and Issues Obtainable at Center for Sustainability Research and Consultancy \\
Journal of Accounting and Finance in Emerging Economies \\
ISSN: 2519-0318 ISSN (E) 2518-8488 \\
Volume 5: Issue 1 June 2019 \\
JSRᄃ \\
Journal homepage: $\underline{\text { www.publishing.globalcsrc.org/jafee }}$ \\
\hline
\end{tabular}

\title{
Investor Sentiments and Trading Volume's Asymmetric Response: A Non-linear ARDL Approach Tested in PSX
}

\author{
${ }^{1}$ Irum Saba, ${ }^{2}$ Maria Shams Khakwani, ${ }^{3}$ Rehana Kouser, ${ }^{4}$ Abdul Wahab \\ ${ }^{1}$ Assistant Professor, IBA Karachi, Pakistan, Email: isaba@iba.edu.pk \\ ${ }^{2}$ Lecturer, Institute of Management Sciences, The Women University, Multan, Pakistan. \\ Email: maria.shams@wum.edu.pk \\ ${ }^{3}$ Professor, Department of Commerce, Bahauddin Zakariya University, Multan, Pakistan. Corresponding Author: \\ Email: rehanakousar@bzu.edu.pk \\ ${ }^{4}$ MPhil Scholar, Department of Commerce, Bahauddin Zakariya University, Multan, Pakistan. \\ Email: abdulwahabdanish@yahoo.com
}

\begin{tabular}{|c|c|}
\hline ARTICLE DETAILS & ABSTRACT \\
\hline History & \multirow{8}{*}{$\begin{array}{l}\text { The research paper entitled "Investor sentiments and trading volume's } \\
\text { asymmetric response: A non-linear ARDL approach tested in PSX" is an } \\
\text { attempt to investigate the dynamic linkages between trading volume and } \\
\text { investor sentiments for Pakistan Stock Exchange (PSX) } 100 \text { index. Two } \\
\text { sentiments indicators have been used to enlighten the linkages. These } \\
\text { indicators are overconfidence and net optimism and pessimism. Trading } \\
\text { volume has been used as a proxy for the measurement of market liquidity. } \\
\text { Non-Linear Asymmetric Autoregressive Distributed Lag (NARDL) as } \\
\text { well as Dynamic Conditional Correlation (DCC) GARCH have been used } \\
\text { to explain the dynamic linkages between trading volume and investor } \\
\text { sentiments. Empirical findings suggested an asymmetric long-term market } \\
\text { liquidity reaction to investor sentiment as well as upcoming three-year } \\
\text { correlation have been forecasted between the trading volume and investor } \\
\text { sentiments. In the short term, stock market liquidity reacts rapidly and } \\
\text { asymmetrically to changes in overconfidence sentiment while the net } \\
\text { optimism and pessimism sentiment have insignificant short-term impact } \\
\text { on trading volume. }\end{array}$} \\
\hline d format: May 2019 & \\
\hline Available Online: & \\
\hline & \\
\hline & \\
\hline & \\
\hline JEL Classif & \\
\hline D92, C50, C59 & \\
\hline
\end{tabular}

(C) 2019 The authors, under a Creative Commons Attribution-Non Commercial 4.0

Corresponding author's email address: rehanakousar@bzu.edu.pk

Recommended citation: Saba, I., Khakwani, M. S., Kouser, R. and WahabA. (2019). Investor Sentiments and Trading Volume's Asymmetric Response: a Non-linear ARDL Approach Tested in PSX. Journal of Accounting and Finance in Emerging Economies, 5 (1), 47-56

DOI: $10.26710 /$ jafee.v5i1.720

\section{Introduction}

Naturally, when the investor is in the phase of optimism, he thinks that the investment in the stocks will give him the gains he required while the negative sentiment or the influence of negativity on the trading volume will have a huge impact on trading as investors avoid to invest in the stock exchange. They are demonstrated by their wants when the phase of optimism is heavier as compared to pessimistic phase. The reaction of the investors is also very strong in the market in this phase while on the other hand, when there is no advancement in the returns then they 
avoid doing the trading. In each scenario, the trading volume is the best indicator used for the investor sentiments as it can easily tell us whether the investors are optimistic or pessimistic as a whole in the market.

Investors control their craving as demonstrated by the availability of new information and this strategy influences on the trading volume of the stock exchange. To check the proportion of the data, two concepts are very important in reference with the investor sentiment as the following two concepts are of pivotal importance in the association of investor sentiment and the asymmetric response of trading volume. These are; (i) Returns (ii) Trading volume. These two domains are seen differently in standard finance and behavioral finance.

Where Standard Finance accepts people as completely educated, mindful and judicious, Behavioral Finance displays the people as ordinary individuals that are not constantly reasonable and are affected by feelings, patterns, observations, heuristics and predispositions (Statman, 1999). In this way, it becomes very difficult to see the patterns of the returns and trading volume without having a grip on the investor sentiment. In this case, over reaction as well as under reaction of the investors should be observed in order to see the impact of investor sentiment on the trading volume. Overreaction and under reaction are the wonders which make a contrast between Traditional Finance and Behavioral Finance. Market productivity has been acknowledged by previous researchers and experts regarding "beat the market" (Jo and Kim, 2008). Surveying financial specialist's psychological perceived research, two noteworthy responses of market to a great extent revealed in writing are over reaction and under reaction of investors. Financial specialist acknowledged as silly in choices, either under reaction or over reaction to each occasion or new information. Under reaction here allude to the reaction of financial specialists to a news landed in advertisements not as much as what is normal for them. At the point when the market responds to some news quickly after its release and keeps on responding even in consequent period, the response is named as under reaction (Prast, 2004). Correspondingly response of financial specialists to a progression of news more noteworthy than what is normal is called over reaction. An instance of overreaction is unique in relation to that of under reaction, i.e. Reaction of market to progressing news is adjusted by modification in an opposite course in resulting periods.

Over reaction gave rise to momentum and inversion. In 1998, Nicholas, Shliefer and Vishny recognized two types of organizations. One is the mean returning administration and the other is the slope administration in which organizational benefits run. It is more plausible that mean returning wage will stay in present administration thus money related authorities revive their feeling about which state they are in, with every loud and clear news. The under reaction of the investors based on the momentum are of the view that investors will tend to under react where the signs of trading will be negative so that they might also ignore the positive signs in the market just because of under reaction stage (Spellman, 2009).

Many of the studies have focused that stock returns are linked with the short term lag and its adjustment with price. Now the studies have their focus on the market, how the existence of a long term return with the fluctuation in the prices of the stocks react. Long term over reaction to the information or under response, can recognize inefficiency, only in a long term investigation (Fama, 1998). Cognitive psychology related review provides an effective and strong base to interpret investor's behavior and any abnormalities in the stock exchange market. For instance, with the proof of over reaction of investor it is trusted that, by and large, speculators may have a tendency to blow up to new information by overlooking base rates. Irrelevant points of reference derive the decisions of the investors. Under and over reaction of financial specialists encourages the examiners to conjecture the future stock returns by showing the regime setting, i.e. a positive information, for example, acquiring declaration would be trailed by the eruption of financial specialists and a progression of positive returns (Michael, 1993).

Reversion is the upward or descending change in accordance with the early expected prices. After a progression of negative revisions, the likelihood of an upward update is around one out of four notwithstanding, after the principal upward correction likelihood winds up one in two. After two upward revisions (after a progression of negative corrections) likelihood of next positive revision is sure turned out to be seven in ten (Goldstein, 1998). Financial specialists stay their future choices with the past occasion, i.e. earlier reversion. Since financial specialists are the most important part of the market, they may over react for the same information under various market situations, at various levels.

After utilizing month to month securities exchange information of PSX 100 index over the period from January 1, 2000 to September 29, 2017, the results confirm that there exists an asymmetric relationship between the market 
liquidity and overconfidence and optimism as well as pessimism perception of the investors. Over and under confidence of investors are based on the overreaction as well as under reaction of stocks market.

\section{Literature Review}

Behavioral finance has a wide scope to explain the investor sentiment as we are very well aware that the theory has explained the investor sentiment with full knowledge and different biases of the investor sentiment. It assumes that people are normal not rational all the time and investor sentiments has impact on its decision.

Ongoing discoveries showed that this isn't a normal phenomenon. Similarly researchers inclined to predispositions as the population everywhere, except in a few circumstances they might be much more inclined to show overconfidence and herding behavior and also investment (Thaler, 2005). In any situation, financial specialists with problematic investments are not totally wiped out from the market. As such, there are points of confinement to arbitrage, and behavioral finance formalizes and set ways; this may occur. One-way behavioral finance formalizes the likelihood of restricted arbitrage is through the noise trader model, which is seemingly a standout amongst the most cited options in contrast to the Efficient Markets worldview. As investors are risk aversive and have short term plans; as claimed by the model, while arbitrageurs don't want to expose themselves to non-diversifiable risk, should be observed by the real life arbitrage (DeLong, Shleifer, Summers \& Waldmann, 1990).

In spite of the fact that noise traders have no entrance to insider data, they exchange on noisy sentiment as though it was important data that would give them an edge on the exchange floor (Black, 1986). Noise traders are very touchy to the variances in the sentiments and also they overestimate the expected returns in some of the periods. Changes in the stocks return similar developments can be due to changes in the essential need or the rebate rate. We can say that the linkage of noise traders and arbitrageurs can be controlled with the help of the stock prices while there will be no standing position of the macroeconomic factors or the risk factors. To further clarify the phenomenon, we assumed the investor sentiment as a means with the help of classical finance theory so that the concept be further clarified.

Investor sentiment is of pivotal importance in this research paper as the asymmetric behavior of the trading volume has been observed in reference with the investor sentiment. Yet in the previous literature, investor sentiment is based on the different actions or performances of the investor like the over confidence, under confidence and optimism as well as the pessimistic behavior of the investors in the financial market. The term investor sentiment in itself is a liability of the huge range of cartels and is utilized in various researches by the scholars, financial experts (Barberis \& Vishny, 1998). More correctly, we characterize the investor sentiment as the two potential outcomes for why mistaken beliefs happen, people effectively utilize wrong information, or that they wrongly utilize or amend the information. At the end of the day, sentimental investors may refresh their convictions through news about essentials notwithstanding loud signals random to basics, and may do as such in a way that is measurably inaccurate. Sentiment can be used as part of the assumptions linked with the stock returns.

\section{Methodology}

Information is collected over the monthly time period in order to estimate the influence of the investor sentiment on the trading volume. The data related to the trading volume and investor sentiment is collected from Pakistan stock exchange. Both types of financial and nonfinancial sectors have been discussed in the data. Monthly data set has been taken for the trading volume which is used as, "the proxy for the stock market liquidity". Investor sentiment data has been calculated by regressing the macroeconomic indicators against trading volume and then taking value of residuals as investor sentiments. The macroeconomic variables are Producer Price Index, Consumer Price Index, Industrial Production, Money Supply, Capacity Utilization Rate, Long Term Government Yield and GDP per capita.

The sample period is taken from January 2000 to December 2017. Previously no study has been done on the asymmetric response of trading volume and investor sentiment. Trading volume has been calculated monthly while the investor sentiments data has also been calculated on the monthly basis. Main motivation of this study is that no one has previously done any work on the trading volume and investors sentiments. Investor sentiments has its partial sums which are positive and negative and this series will be used in order to obtain results regarding the asymmetric response of trading volume due to investor sentiments in the Pakistan stock exchange. 
In order to estimate association between investor sentiments and trading volume, data is of the PSX 100 index monthly from 31 January 2000 to 29 December 2017. Data of trading volume is available in PSX 100 index website while investor sentiment has been calculated by regressing the macroeconomic indicators. In this research, we have used trading volume as proxy for liquidity of stock market. Natural logarithm of transaction volume has been taken. Grossman and Miller (1988) also measured stock market liquidity by estimating the trading volume.

While calculating investor sentiment, regressing the macroeconomic indicators and taking only the residual will allow us to supervise optimism as well as pessimism condition of the investors. If there is an increase in the indicator then it is considered as the positive or optimistic perception of the investor while on the other hand if there is a decrease in the indicator shows that the perception of the investor is pessimistic for future stock market reaction. Over and under confidence is also dependent on the investor's positive and negative sentiments which is linked with the overreaction and under reaction of stocks in the stock exchange market.

Linear models which are assumed in symmetric relationships dominate the existing literature on the stock price and trading volume. Many researchers have focused on the asymmetry relationship while few have focused nature of equilibrium over time and co integration models which allow short term and long term relationship. NARDL has its own way of estimating the variables which is different from the conventional models of co integration.

\subsection{Dynamic Conditional Correlation (DCC) GARCH}

There was an evolution of multivariate GARCH which was introduced in 1990 by Bollerslev. It is used for the purpose of checking the dynamic linkages between the variables. In this research, we have applied this dynamic conditional correlation between the trading volume and investor sentiment and turnover ratio and investor sentiment and also stock return and investor sentiment so that we are able to understand the linkages between these variables and will know the behavior of these variables.

It is the advanced technique used for the purpose of more explanation and clarification of the correlation between the variables. We calculate DCC GARCH by using R-Programing language and displayed multiple graphs for forecasting.

\subsection{Bound Tests for Non-Linear Co integration}

When series are integrated at different orders then there is need to perform a co integration test to confirm the longterm association between the variables. Here Johansen co integration test cannot be applied as it is not valid one for the estimation of long-term relationship. In 2001, Pesaran, Shin and Smith proposed a new technique of co integration estimation which is known to be the Bounds test of co integration. The null hypothesis of bounds test is that there is no co integration between the variables. We have applied this test in order to check the existence of co integration of variables. In this test, if the value of F- stats is greater than the critical value then there exists cointegration between the variables while on the other hand if the F-stats value is less than the critical values then there is no existence of co integration between the variables. We have applied this test in this paper to check the linkage between trading volume and investor sentiments in order to investigate either they are co-integrated or not. If the F-stats value is between the critical upper and lower values, then it means that there is no use of bound test or it is of no use to check the inter linkages between the variables.

\subsection{Non-Linear Auto Regressive Distributed Lag Model}

In order to test the asymmetric response of trading volume and investor sentiment, we have applied non-linear auto regressive distributed lag (NARDL) model for the variables. Unit root tests have been applied to check the integrated level of data; whether the data is integrated at zero level or first difference or the second difference. Error correction model (ECM) is used under NARDL method in order to estimate the long run and short run relationships of the variables i.e. trading volume and investor sentiment.

\section{Results \& Discussion}

\subsection{Conditional Correlation and Forecast Graph}

To check the inter linkage between trading volume and investor sentiment, we have applied dynamic conditional correlation (DCC), a technique used for the estimation of correlation. Following is the graph between trading volume and investor sentiment which is showing a decrease in correlation between these two variables with the passage of time. From 2000 to 2017, there is a symmetric pattern of correlation between these two variables while in the upcoming years, this trend is going to be weak. 


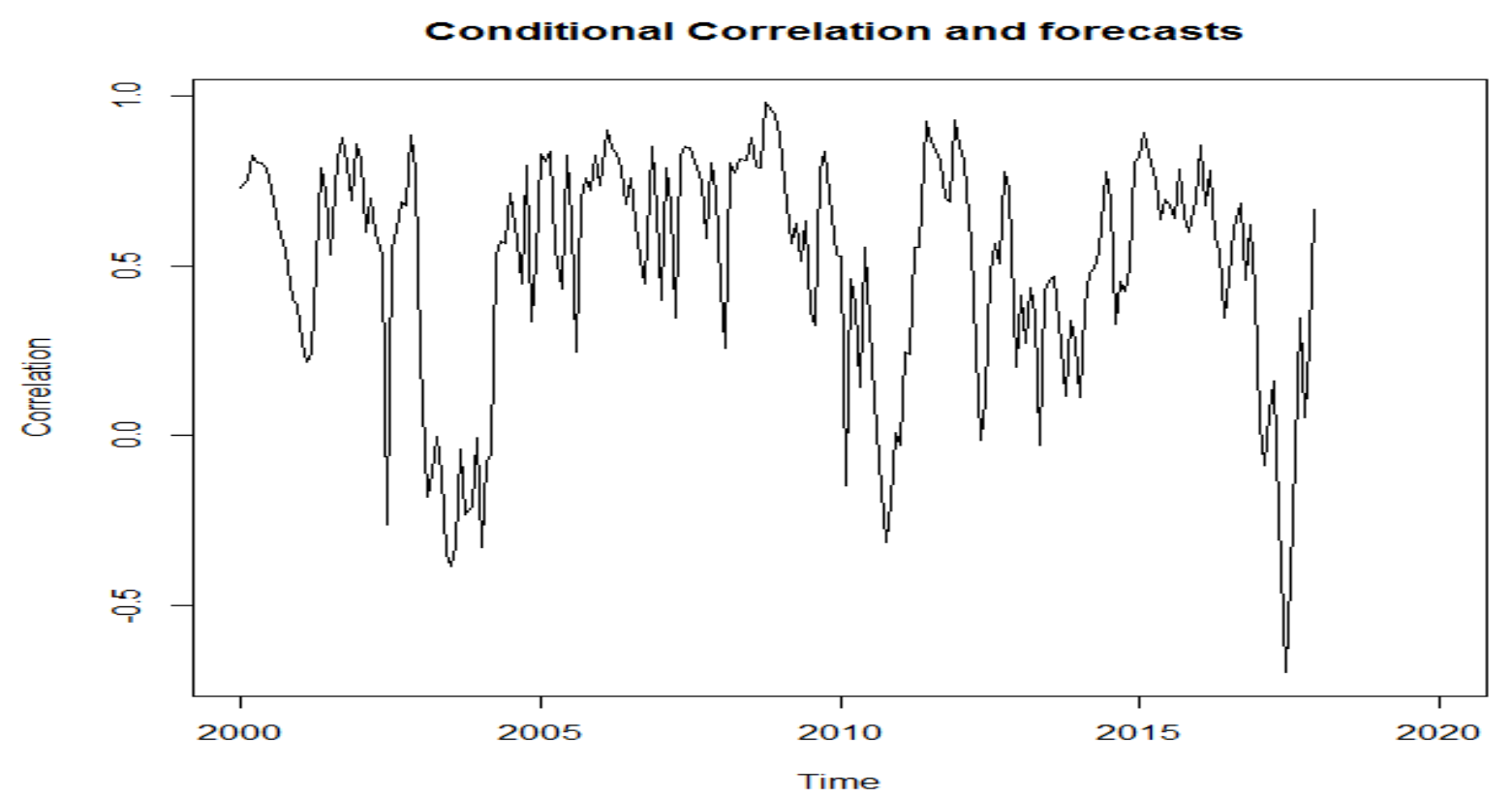

\subsection{Estimation of Probabilities}

In the following table 1, it can be seen that the mean of the two variables, trading volume and investor sentiment, is zero which fulfills the assumption of the correlation model (Engle, 2000). This model, introduced by Box and Jenkins, is considered to be the best model used for forecasting and is based on the past values as well as the errors relating to past values. GARCH is appropriate because alpha 1 in both scenarios, trading volume and investor sentiment, is less than 0.05. Dynamic conditional correlation (DCC) is significant as the value of dccal is significant.

\section{Table 1}

$\begin{array}{lll} & \text { Estimate } & \text { Standard Error } \\ \text { [Trading.Value].mu }(\mathrm{u}) & 11.20346^{* * *} & 0.086904 \\ \text { [Trading.Value].omega } & 0.127277^{*} & 0.066888 \\ \text { [Trading.Value].alpha1 } & 0.670161^{* * *} & 0.206296 \\ \text { [Trading.Value].beta1 } & 0.328839^{* *} & 0.142935 \\ \text { [sentiments].mu } & 1.85 \mathrm{E}-05 & 0.101533 \\ \text { [sentiments].omega } & 0.123422 & 0.082407 \\ \text { [sentiments].alpha1 } & 0.593981^{* *} & 0.286823 \\ \text { [sentiments].beta1 } & 0.320863 & 0.272661 \\ \text { [Joint]dcca1 } & 0.4166^{* * *} & 0.123677 \\ \text { [Joint]dccb1 } & 0.383315 & 0.237648\end{array}$

\subsection{Forecasting Outcomes}

In table 2, we can see a decreasing pattern in the forecasted values between trading volume and investor sentiment. 3 year's forecasts has been calculated for trading volume and investor sentiment which shows that the correlation between these two variables is higher in 2018 as compared to 2019 and 2020. The value in January 2018 is the highest one among all values forecasted for these two variables. Table 2 highlighted that in upcoming 8 months of 2018, values are decreasing with a fast pace while from October 2018 to December 2020, the rate of decrease in the value is not very significant. This exhibits the existence of correlation between these two variables in the upcoming years and there is stream lined pace of values in the coming period. 
Table 2

\begin{tabular}{|l|l|l|l|l|l|l|}
\hline 1 & 0.607119 & Jan-18 & 0.536809 & Jan-19 & 0.531983 & Jan-20 \\
\hline 2 & 0.592014 & Feb-18 & 0.535772 & Feb-19 & 0.531912 & Feb-20 \\
\hline 3 & 0.579932 & Mar-18 & 0.534943 & Mar-19 & 0.531855 & Mar-20 \\
\hline 4 & 0.570267 & Apr-18 & 0.534279 & Apr-19 & 0.53181 & Apr-20 \\
\hline 5 & 0.562536 & May-18 & 0.533749 & May-19 & 0.531773 & May-20 \\
\hline 6 & 0.556351 & Jun-18 & 0.533324 & Jun-19 & 0.531744 & Jun-20 \\
\hline 7 & 0.551404 & Jul-18 & 0.532985 & Jul-19 & 0.531721 & Jul-20 \\
\hline 8 & 0.547447 & Aug-18 & 0.532713 & Aug-19 & 0.531702 & Aug-20 \\
\hline 9 & 0.544282 & Sep-18 & 0.532496 & Sep-19 & 0.531687 & Sep-20 \\
\hline 10 & 0.54175 & Oct-18 & 0.532322 & Oct-19 & 0.531675 & Oct-20 \\
\hline 11 & 0.539725 & Nov-18 & 0.532183 & Nov-19 & 0.531666 & Nov-20 \\
\hline 12 & 0.538105 & Dec-18 & 0.532072 & Dec-19 & 0.531658 & Dec-20 \\
\hline
\end{tabular}

\section{Descriptive Statistics}

In table 3, the descriptive statistics of independent and dependent variable is shown. Mean, median, maximum and minimum values can be seen as well as standard deviations and skewness of variables. kurtosis that measures the flatness of the distribution of the series is also provided. In the following descriptive statistical analysis, we can see that with respect to trading volume, kurtosis value is 11.07 which is greater than 3 means trading volume data has a long right-tail or it is leptokurtic. In case of turnover ratio, kurtosis is again greater than 3 which means data is positively skewed. In investor sentiments, value of kurtosis is again very high meaning that the data is leptokurtic. Jarque bera test tells the difference between skewness and kurtosis and in this case, the probability in all 3 cases is $<0.05$ so we are able now to reject the null hypothesis of a normal distribution. Probability values are highly statistically significant in all these cases.

Table 3

\begin{tabular}{|l|l|l|l|}
\hline & TRADING VOLUME & TURNOVER_RATIO & SENTIMENTS \\
\hline Mean & 162263.5 & 0.007904 & $1.85 \mathrm{E}-07$ \\
\hline Median & 85582.17 & 0.003007 & 0.119915 \\
\hline Maximum & 1175086. & 0.051948 & 2.112180 \\
\hline Minimum & 4.228000 & $1.52 \mathrm{E}-07$ & -12.40899 \\
\hline Std. Dev. & 191570.4 & 0.009732 & 1.240449 \\
\hline Skewness & 2.556562 & 1.851231 & -5.907399 \\
\hline Kurtosis & 11.07639 & 6.421958 & 53.97119 \\
\hline Jarque-Bera & 822.3485 & 228.7623 & 24638.87 \\
\hline Probability & 0.000000 & 0.000000 & 0.000000 \\
\hline Sum & 35048910 & 1.707171 & $4.00 \mathrm{E}-05$ \\
\hline Sum Sq. Dev. & $7.89 \mathrm{E}+12$ & 0.020362 & 330.8233 \\
\hline Observations & 216 & 216 & 216 \\
\hline
\end{tabular}

\subsection{Unit Root Tests}

Before the inspection of the dynamic relationship between trading volume and investor sentiment, we have to test the stationarity in the data. For this purpose, we have to first check the integration level of variables. Kwiatkowski Phillips Schmidt Shin (KPSS), Phillips Perron (PP) and Augmented dickey fuller test (ADF) test have been applied in order to check the unit root. All the variables are integrated at 0 levels and 1(1) while no variable has been integrated at level 2, as given in table 4. Therefore, NARDL model can be applied for the estimation of long term as well as short term. 


\section{Table 4}

\begin{tabular}{|l|c|c|c|}
\hline & ADF & PP & KPSS \\
\hline In Level & Level ADF test statistics & Level PP & \\
\hline TV & $-5.560744^{* * *}$ & $-5.440897^{* * *}$ & $0.298134^{* * *}$ \\
\hline Sent & $-8.365074 * * *$ & $-8.920060^{* * *}$ & $0.037436^{* * *}$ \\
\hline TR & $-4.581513^{* * *}$ & $-4.319988^{* * *}$ & 1.571874 \\
\hline In Difference & & & \\
\hline TV & -13.30390 & -25.84360 & 0.104773 \\
\hline Sent & -11.39569 & -77.55767 & 0.171487 \\
\hline TR & -10.61581 & -34.98368 & 0.382828 \\
\hline
\end{tabular}

\subsection{Bounds Test for Non Linear Co integration}

When the series is integrated at different orders, then there is need to perform a cointegration test to confirm the long term association between the variables. Here, Johansen cointegration test cannot be applied as it is not valid one for the estimation of long term relationship. In 2001, Pesaran, Shin and Smith proposed a new technique of cointegration estimation known as Bounds test of cointegration. The null hypothesis of bounds test is that there is no cointegration between the variables. As given in table 5, the value of $\mathrm{F}$ stats explains that the investor sentiment and trading volume move in the same direction for a longer period. In the following scenario, value 4.736488 of $\mathrm{F}$ stats exceeds the critical lower bound and upper bound at $10 \%$ significance level and 5\% significance level respectively. Based on the following result of F-Statistics, we can say that there exists a long term association between trading volume and investor sentiment.

\section{Table 5}

\begin{tabular}{|c|c|c|c|}
\hline F-Stats & Lower Critical Value & Upper Critical Value & Result \\
\hline 4.736488 & 3.17 & 3.79 & Co integration \\
\hline
\end{tabular}

\subsection{Non-Linear Auto Regressive Distributed Lag Model}

As in this case, we need to check the relationship between trading volume and investor sentiments and assess the impact of investor sentiments' positive and negative change in the trading volume. In the above applied tests unit root of the investor sentiments and trading volume is clear and data is stationary at zero integrated level. In order to verify the following equation, we applied non linear auto regressive distributed lag.

$$
\mathrm{TV}_{\mathrm{t}}=\mathrm{C}+\text { Sent }_{\mathrm{t}}+\mu_{\mathrm{t}}
$$

In the above equation, $\mathrm{tv}$ is the trading volume while sent has been used as investor sentiment. We created the partial sum of positive and negative change in the investor sentiments. Sent_p and Sent_n are the positive investor sentiment and negative investor sentiments respectively, which are drawn from the investor sentiment. Error correction model has been run under nonlinear autoregressive distributed lag.

Following are the results of NARDL which explain the impact of investor sentiments on the trading volume, but in order to interpret the results, we calculated the long run coefficients as Eviews removed some of the lags while running the model. In case of positive sentiment, the value is 0.056060 and in negative sentiment, it is 0.057733 . Both values have been divided by the trading volume value -0.093054 in order to attain the long run coefficients. Both the coefficients are positive; the values of positive sentiment and negative sentiment are 0.60244 and 0.62042 respectively. Thus, the equation is written as;

$$
\operatorname{Tv}=0.60244 \text { sent }_{p}+0.62042 \text { sent }_{n}+\mu
$$

It shows that the $1 \%$ increase in positive sentiment will lead to 0.60244 percent increase in the trading volume at the stock exchange while on the other hand, $1 \%$ decrease in negative sentiment of the investor leads to 0.62042 percent decrease in the trading volume. 


\begin{tabular}{lll} 
Variable & Coefficient & Std. Error \\
C & $1.266446 * *$ & 0.530180 \\
TV(-1) & $-0.093054 * *$ & 0.039428 \\
SENT_P(-1) & 0.056060 & 0.056810 \\
SENT_N(-1) & 0.057733 & 0.057040 \\
DSENT_N & $0.933133 * * *$ & 0.058542 \\
DSENT_P & $0.658079 * * *$ & 0.050664 \\
DSENT_N(-1) & $0.510285 * * *$ & 0.097016 \\
DTV(-1) & $-0.431887 * * *$ & 0.072499 \\
DTV(-3) & $-0.124985 * *$ & 0.060201 \\
DSENT_P(-3) & $0.175339 * * *$ & 0.054608 \\
DSENT_P(-2) & $0.207596 * * *$ & 0.052937 \\
DTV(-2) & $-0.268550 * * *$ & 0.061559 \\
DSENT_P(-1) & $0.207160 * * *$ & 0.053694 \\
\multicolumn{3}{c}{} \\
R-squared & 0.834585 & \\
Adjusted & R- & \\
squared & 0.824611 & \\
\multicolumn{2}{c}{ Prob (F-statistic) 0.000000} &
\end{tabular}

\section{Conclusion}

The paper examines the dynamic association between the trading volume and the investor sentiment of Pakistan stock exchange. The main contribution of this research paper is that it provided a deep rooted analysis for the short term as well as long term change in the trading volume with respect to the investor sentiment. In this study, DCC Garch has been used for the purpose of estimating a correlation between the trading volume and the investor sentiment. By the help of R-language, we provided forecasted values for the upcoming three years, that can be utilized in the future studies. Nonlinear cointegration approach termed as Asymmetric Autoregressive Distributed Lag (NARDL) has been employed to provide estimation of the short term as well as long term asymmetry between the trading volume and investor sentiment.

The research is performed on the monthly data from 1st January 2000 to 31st December 2017. The results confirmed that there exists a long-term asymmetry between trading volume and investor sentiment. Results also highlighted that the positive investor sentiment causes an increase in the trading volume as the investors are considered to be in over confidence phase while on the other hand the negative investor sentiment causes a decrease in the trading volume as the investors are in the phase of pessimism.

These results are consistent with the over confidence bias of behavioral finance which proposes that over confidence of investor causes an increase in the extreme trading while under confidence of investors slackens trading in the stock exchange. When the investors are in bad phase or in the condition of under confidence, they should not avoid trading so that they will be able to overcome the impact of under confidence and ultimately perceptions will be changed to optimism. This will help investors to streamline their portfolios by making good investment or decision making regarding the future stocks returns.

\section{References}

Barberis, N., Shleifer, A., \& Vishny, R. (1998). A model of investor sentiment. Journal of financial economics, 49(3), 307-343.

Black, F. (1986). Noise. The journal of finance, 41(3), 528-543.

Bollerslev, T. (1990). Modlling the coherence in short-run nominal exchange rates: a multivariate generalized ARCH model. The review of economics and statistics, 498-505.

Chiu, T. L., \& Goldstein, R. A. (1998). Optimizing potentials for the inverse protein folding problem. Protein engineering, 11(9), 749-752.

Durinck, S., Spellman, P. T., Birney, E., \& Huber, W. (2009). Mapping identifiers for the integration of genomic datasets with the R/Bioconductor package biomaRt. Nature protocols, 4(8), 1184. 
Engle, R. F. (2000). Financial econometrics-a new discipline with new methods.

Fama, E. F. (1998). Market efficiency, long-term returns, and behavioral finance1. Journal of financial economics, 49(3), 283-306.

Grossman, S. J., \& Miller, M. H. (1988). Liquidity and market structure. The journal of finance, 43(3), 617-633.

Jo, S., Kim, T., Iyer, V. G., \& Im, W. (2008). CHARMM-GUI: a web-based graphical user interface for CHARMM. Journal of computational chemistry, 29(11), 1859-1865.

Markowitz, H. (1952). Portfolio selection. The journal of finance, 7(1), 77-91.

Michael, P., Patrick, B., \& Ulric, N. (1993). Cognitive Psychology. The American Journal of Psychology, 105, 621673.

Odean, T. (1999). Do investors trade too much? American economic review, 89(5), 1279-1298.

Pesaran, M. H., Shin, Y., \& Smith, R. J. (2001). Bounds testing approaches to the analysis of level relationships. Journal of applied econometrics, 16(3), 289-326.

Prast, H. M. (2004). Investor psychology: A behavioural explanation of six finance puzzles: De Nederlandsche Bank Amsterdam.

Shefrin, H., \& Statman, M. (2000). Behavioral portfolio theory. Journal of financial and quantitative analysis, 35(2), 127-151.

Shleifer, A., DeLong, J. B., Summers, L. H., \& Waldmann, R. J. (1990). Noise trader risk in financial markets. Journal of Political Economy, 98(4), 703-738.

Statman, M. (1999). Behaviorial finance: Past battles and future engagements. Financial Analysts Journal, 18-27.

Thaler, R. H. (2005). Advances in behavioral finance (Vol. 2): Princeton University Press. 
